\title{
ESTADO E PROPRIEDADE NA DOUTRINA DO DIREITO DE KANT
}

\author{
José N. Heck**
}

SÍNTESE - o artigo sumaria o modo peculiar como Kant lida com o estado de natureza hobbesiano e estabelece o espaço público do meum vel tuum externum na Doutrina do Direito. O texto visa realçar a originalidade de Kant como filósofo político.

PALAVRAS-CHAVE - Kant, direito racional, propriedade, razão prática.
ABSTRACT - The article summarizes the peculiar way in which Kant deals with Hobbes' state of nature establishing the public space ot the meum vel tuum externum in his Doctrine of Right. The text pretends to show the extent of Kant's originality as a political thinker.

KEY WORDS - Kant, rational law, property, practical reason.

\section{Introdução}

Estudos recentes dos textos tardios de Kant (1724-1804) lançam nova luz sobre a arquitetônica concepcional do filósofo transcendental. Relegada durante muito tempo ao ostracismo filosófico, a Metafísica dos costumes (1797) volta a ser objeto de investigações pormenorizadas. A dedução da propriedade é vista como o último grande feito transcendental de Kant, ${ }^{1}$ ou saudada como logomarca de uma teoria crítica do Estado moderno ${ }^{2}$ Com isso, as relações de Kant com os dois clássicos da filosofia política moderna, Hobbes (1588-1679) e Rousseau (1712-1778), tornam-se movediças no front acadêmico. A aparente proximidade com o genebrino cede lugar à recepção crítica do teórico político inglês.

* Comunicação feita no II Congresso Kant - 200 anos da Metafisica dos Costumes - em Itatiaia (8 dez 1997).

** Professor da Universidade Federal de Goiás, UFG/CNPq.

1 KERSTING, Wolfgang. Wohlgeordnete Freiheit. Immanuel Kants Rechts- und Staatsphilosophie. Berlin/New York: Gruyter, 1984, X. Cf. também LUDWIG, Bernd. Kants Rechtslehre. Hamburg: Meiner, 1988.

2 HERB, Karlfriedrich, LUDWIG, Bernd. Kants kritisches Staatsrecht. In: Annual Review of Law and Ethics (1994), p. 431-478. Cf. também GERHARDT, Volker. Eine kritische Theorie der Politik über Kants Entwurf Zum ewigen Frieden. In: ROHDEN, Valério (coord.). Kant e a instituição da paz. Porto Alegre: Ed. Universidade-UFRGS \& Goethe-Institut-ICBA, 1997, p. 19-38; versão portuguesa, p. 39-57. 


\section{A carga dialética do state of nature hobbesiano}

O pacto hobbesiano assinala o universo dialético sócio-político moderno in statu nascendi. ${ }^{3}$ Disso Hegel (1770-1831) tirou a conclusão, ${ }^{4}$ dialetizando o que conferira, em Hobbes, dignidade filosófica ao contratualismo. Hegel concebe o pacto, enquanto mútua transmissão de direitos, como mera negação do estado de guerra natural, ou seja, o pacto hobbesiano não passa da renúncia recíproca de todos à possibilidade de cada um impedir o exercício do direito à vida dos demais, com vistas à preservação física de cada contratante. Para Hegel, o estado natural do homem não é suprassumivel pela autoconservação da natureza, mas sim por uma concepção substancial de liberdade. O Estado deixa de ser resultado de um cálculo de sobrevivência individual e se torna a realização por excelência da filosofia prática (Filosofia do Direito, parágrafo 260). Visto a partir do resultado, o mérito de Kant foi haver desativado a bomba dialética da teoria estatal do pensador inglês e tê-la reposta nos termos de uma normatividade jurídica no horizonte do direito racional da época.

Hobbes não foi apenas o apologeta do Estado absoluto, mas também o teórico de uma constelação de poder que garante a cada indivíduo o deleite de sua liberdade sob leis formuladas pelo árbitro-soberano. ${ }^{5} \mathrm{O}$ Estado hobbesiano näo é tirânico, com um chefe de Estado voluntarista à sua testa. Os subordinados ao mando político absoluto não são fora-da-lei, mas personagens políticas com direitos concedidos (granted) por lei civil, bem como direitos naturais negativos, que lhes foram deixados (left) pelas leis civis, ${ }^{6}$ ou seja, tudo o que não estiver regulamenta-

3 Cf. HABERMAS. Die klassische Lehre von der Politik in ihrem Verhältnis zur Sozialphilosophie. In: Theorie und Praxis. 3. Aufl. Frankfurt a/Main, 1974, p. 48-88.

HEGEL, Georg-W. Wissenschaftliche Behandlungsarten des Naturrechts, seine Stelle in der praktischen Philosophie, und sein Verhältnis zu den positiven Rechtswissenschaften. In: Jenaer Kritische Schriften (II). Hrsg. von Hans Brockard und Hartmut Buchner Hamburg: Meiner, 1983, p. 90-178. Cf. BENJAMIN, Cássio C. Hegel e os três modos de passagem do Estado de Natureza ao Estado de Direito no jusnaturalismo moderno. In: Ética e Filosofia Politica, v. 2, n. 1, jan./jun. 1997, p. 93-108.

5 HOBBES, Thomas. The cive or the citizen. Ed. by Sterling P. Lamprecht. Westport, Conn.: Greenwood Press, 1982, p. 74-75: "It belongs to the same chief power to make some common rules for all men, and to declare them publicly, by which every man may known what may be called his, what another's, what just, what unjust, what honest, what dishonest, what good, what evil, that is summarily, what is to be done, what to be avoided in our common course of life. But those rules and measures are usually called the civil law, or the law of the city, as being the commands of him who hath the supreme power in the city. And the civil laws (that we may define them) are nothing but the commands of him who hath the chief authority in the city, for direction of the future actions of his citizens". Trad. do latim/inglês por Renato J. Ribeiro. São Paulo: Martins Fontes, 1992, p. 119. Cf. também MADANES, Leiser. Hobbes e o poder arbitrário. In: Discurso, 28, 1997, p. 89-126.

Ibidem, p. 151. "But because all the motions and actions of subjects are never circumscribed by laws, nor can be, by reason of their variety, it is necessary that there be infinite cases, which are neither comanded, nor prohibited, but every man may either do, or not do them, as he lists himself. In these, each man is said to enjoy his liberty; and in this sense liberty is to be understood in this place, namely, for that part of natural rights, which is granted and left to subjects by the civil laws". Versão portuguesa, p. 233. Para a relação entre o pensamento hobbesiano e os direitos políticos básicos cf. STRAUSS, Leo. The political philosophy of Hobbes. Chicago: University of Chicago Press, 1952. 
do, devido ao silêncio da lei positiva, permanecerá residualmente à disposição da vontade dos súditos. ${ }^{7}$

Kant localiza a excrescência absolutista de Hobbes na passagem do De Cive (1642), onde se lê, na versão inglesa, que o titular do mais alto poder no Estado não tem, por contrato, obrigações em relação a ninguém (are by no compacts obliged to any man), resultando disso, conseqüentemente, que não pode fazer injúria nenhuma aos súditos (it necessarily follows, that they can do no injury to the subjects). ${ }^{8}$ Kant declara que, em sua generalidade, a frase é terrivel (aber so im allgemeinen ist der Satz schrecklich). ${ }^{9}$ Embora a formulação possa ser vista como uma declaração de guerra intelectual, ela faz parte do corolário de um texto cuja introdução assinala o lugar exato onde Kant rompe, por princípio, com a teoria hobbesiana do Estado absoluto e, sob esse aspecto, é mais decisiva que o veredito conclusivo. Kant escreve, referindo-se ao contrato originánio: "Entre todos os contratos pelos quais uma multidão de homens se une para formar uma sociedade (pactum sociale), o contrato que entre eles estabelece uma constituição civil (pactum unionis civilis) é de uma espécie tão peculiar que, embora, quanto à execução, tenha muito em comum com qualquer outro (que visa a obtenção em comum de um outro fim qualquer), no entanto, no princípio de sua constituição (constitutionis civilis) distingue-se essencialmente de todos os demais". ${ }^{10}$ Enquanto todos os outros contratos já ocorrem na sociedade civil, o pacto hobbesiano é feito sem que haja uma sociedade como resultado do contrato originário. Em resumo, o status hominum extra societatem é um estado de direito privado, onde cada um é juiz em causa própria e não está, por conseguinte, em condições de exigir coisa alguma dos demais e muito menos a celebração de um contrato.

Esse fato, Hobbes leva-o em consideração com o chamado estado natural que, segundo ele, importa abandonar por um ato coletivo-recíproco de transferência, capaz de criar um agente autorizado a agir com poder absoluto. Kant não contesta tal necessidade. Mas, nem por isso, refaz o caminho do absolutista, do estado natural ao estado político do homem, por Hobbes conceder ao soberano um poder discricionário à revelia do normativismo racional, livrando-o a limine de toda contradição. Hobbes concebe o medo ante a morte iminente como um conceito isento de contradição, uma vez que é graças a ele que todos os homens são autoconservadores por definição. Deste pavor, idêntico, ao mesmo tempo e sob o mesmo prisma, ao medo que uns têm dos outros, Hobbes constrói a proposição-mor da moderna convivência política, ou seja, medo e liberdade, bem como liberdade e

7 Idem. Leviathan. Ed. by Richard Tuck. Cambridge/New York: Cambridge University Press, 1991, p. 147: "It followeth necessarily, that in all kinds of actions, by the laws praetermitteed, men have the Liberty, of doing what their own reasons shall suggest, for the most profitable to themselves". Trad. do inglês por João P. Monteiro e Maria B. N. da Silva. São Paulo: Abril Cultural, 1974, p. 134. Idem. The cive or the citizen. Ed. by Sterling P. Lamprecht. Westport, Conn.: Greenwood Press, 1982, p. 94. Versão portuguesa, p. 147.

9 KANT, Immanuel. Vom Verhältnis der Theorie zur Praxis im Staatsrecht. In: Über den Gemeinspruch: Das mag in der Theorie richtig sein, taugt aber nicht für die Praxis (II). Hamburg: Meiner, 1992, p. 37. Trad. do alemão por Artur Morão (A paz perpétua e outros opúsculos) Lisboa: Ed. 70, 1988 , p. 90.

10 Ibidem, p. 20; versão portuguesa, p. 73. 
necessidade são compatíveis. ${ }^{11}$ Menos do que a observação de um fato, com tal compatibilidade Hobbes formula a sua concepção de individualidade, ${ }^{12}$ ou seja, por serem principios de não-contradição ambulantes, os indivíduos também não se encontram em contradição uns com os outros. $O$ dado mais elementar do estado de natureza perfaz, concomitante e necessariamente, o elemento-chave do que, para Hobbes, não passa de um artifício - a paz social. Em suma, submeter-se às decisões inapeláveis do soberano político é tão pouco irracional quanto aceitar a morte natural inevitável.

Kant faz da exigência exeundum est e statu naturali um princípio normativo, o "dever incondicionado e primordial dos homens que, como tal, só é localizável em uma sociedade na medida em que se encontra no estado civil, quer dizer, perfaz já um ser comum (ein gemeines Wesen ausmacht)" ${ }^{13} \mathrm{O}$ que Kant objeta é a impossibilidade conceitual do pacto social originánio de estirpe hobbesiana. Para que tal contrato pudesse ser feito, mesmo que fosse apenas na idéia mais perfeita que dele se tivesse, os homens do estado natural teriam que ser o que, segundo Hobbes, não são nesse estado. A liberdade do indivíduo, enaltecida por Hobbes no estado anterior ao pacto, não permite que os seus titulares tenham uma idéia do que seja uma liberdade constituída pelo reconhecimento reciproco do que é meu e do que é teu. O teórico inglês eliminou essa impossibilidade, predicando gratuitamente e, em termos históricos, de forma anacrônica aos supostos homens naturais uma maneira de pensar e um senso civilizatório de sentir que, na verdade, são traços subjetivos da personalidade de Hobbes, um abastado intelectual inglês culturalmente refinado do século XVII. O estado hobbesiano de natureza constitui, assim, uma idealização antropológica racionalizante, possibilitando ao filósofo demonstrar more geometrico que os indivíduos continuam sendo após o pacto 0 que eram antes de o haverem celebrado. $\mathrm{O}$ contrato originário não altera, na ciência política hobbesiana, a natureza humana. "Como, e com que desígnio, os homens se congregam" registra Hobbes, "melhor se saberá observando-se aquelas coisas que fazem quando estão reunidos". ${ }^{14}$ Mesmo vivendo há anos sob as leis do Leviatã, o bem-educado anthropos de proveniência hobbesiana continua sendo um lobo em estado natural.

De acordo com esse raciocínio, Kant critica o teórico inglês do Estado moderno por não indicar o ponto, determinar o princípio ou formular as premissas a partir das quais cada indivíduo, dito natural, possa avaliar o que lhe convém e, muito menos, the dê condições de saber o que é do interesse de todos aqueles que se encontram, segundo Hobbes, em idêntica situação não civil. ${ }^{15}$

11 HOBBES. Leviathan. Ed. by Richard Tuck. Cambridge/New York: Cambridge University Press, 1991, p. 146: "Feare, and Liberty are consistent" - "Liberty and Necessity are consistent"; versão portuguesa, p. 133 e 134.

12 BARBOSA-FILHO, Balthazar. Condições da autoridade e autorização em Hobbes. In: Filosofia Politica 6. Porto Alegre: L\&PM, 1989, p. 64.

13 KANT. Op. cit., p. 20; versão portuguesa, p. 73.

14 "How, by what advice, men do meet, will be best known by observing those things which they do when they are met". The cive or the citizen. Ed. by Sterling P. Lamprecht. Westport, Conn.: Greenwood Press, 1082, p. 22; versão portuguesa, p. 29-30. Cf. MACPHERSON, C. B. The political theory of possessive individualism: Hobbes to Locke. Oxford: Clarendon Press, 1977. 


\section{A idéia de Estado como pura noção jurídica}

Tivesse Kant se limitado a esta crítica, suas observações teriam sido pouco contundentes. $\mathrm{O}$ modelo político hobbesiano continuaria sem alternativa. Os facta bruta articulados por Hobbes, como a ameaça mútua, o medo recíproco da morte, o fato de cada homem só poder sobreviver em paz se a autoconservação dos semelhantes estiver assegurada, todo esse acervo de antagonismos antropológicos não evapora à luz do argumento segundo o qual Hobbes não estaria falando do homem natural, mas sim do homem civil de seu tempo. Tal observação é redundante porque tão-somente ratifica o raio de ação do discurso político de Hobbes. No horizonte do texto Sobre o Dito Comum (1793) Kant não consegue ir além desse tipo de redundância histórico-critica. Não passa de um filosofema sugerir que o efeito vinculador do pacto hobbesiano só pode advir de um fim enquanto dever ${ }^{16}$ ou, então, estatuir o estado civil como pressuposto de um pacto sócio-político, quando o que está em discussão é a conceituação do status civilis. A excelência teleológica de um fim não faz dele ipso facto um contrato. Pelo contrário, quanto mais verdadeiro um télos qualquer é, tanto menos necessidade há para registrá-lo por meio de um contrato. Inversamente, tomar a existência do estado civil como condição deontológica da vinculação política básica é fazer de toda boa hipótese uma peça jurídica.

Mesmo que os membros da sociedade burguesa concordassem, em sua totalidade, que o status civilis corporifica historicamente o que Hobbes alocou para os primórdios da espécie, disso não resultariam deveres contratuais para os agentes sociais e, segundo a moral kantiana, nem sequer uma única obrigação para o homem enquanto ser racional. Hegel não teve dificuldades em mostrar, convincentemente, que os ocasionais sollen valem tanto quanto o müssen dialético-social lhes empresta logicamente ou, como Marx (1818-1883) prefere, o dever de fazer a revolução não vale o esforço da frase se não há condições objetivas para uma situação revolucionária.

Na Doutrina do Direito (1797) Kant põe as coisas de outro modo. Ele apresenta uma dedução original do meu/teu exterior e uma paralela fundamentação jurídica de Estado que justificam a afirmação de que tal foi o último grande feito do filósofo transcendental. ${ }^{17} \mathrm{O}$ modo de proceder de Kant atém-se à distinção, até hoje corrente nas ciências jurídicas, entre direito privado e direito público, mas a conclusão da dupla argumentação jurídico-filosófica é a de que o direito público não compreende nada mais ou outros deveres recíprocos entre os homens do que os que podem ser pensados pelo direito privado. "A matéria do direito privado", apostrofa Kant, "é em ambos exatamente a mesma" (Doutrina do Direito, parágrafo 41).$^{18}$ Kant deixa atrás de si o apriorismo declaratório e põe mãos à obra para constituir um conceito de posse inteligivel (possessio noumenon), concatenando

16 Cf. KERSTING. Kants vernunftrechtliche Staatskonzeption. In: Prima Philosophia 1, 1988, p. 107130.

17 Cf. nota 1.

18 KANT. Metaphysische Anfangsgründe der Rechtslehre. Hrsg. von Bernd Ludwig. Hamburg: Meiner, 1986, p. 124. 
um edificio de argumentos cuja pedra angular é simultaneamente a peça-chave do acabamento da obra: o postulado jurídico da razão prática e a idéia de uma vontade unificada pela reunião do arbítrio de todos (durch vereinigte Willkür Aller). Kant escreve: "Mas a lei distributiva do meu e do teu no solo só pode, de acordo com o axioma da liberdade exterior, surgir de uma vontade originánia e a priori unificada (a qual não supõe, com vistas a essa unificação, ato jurídico algum) [...]."19

A dedução do conceito de posse não-empírica supõe o direito originário de uma liberdade juridica negativa, enquanto independência do arbítrio impositivo de todo outro ser humano. Sua interface positiva é a faculdade humana de autodeterminar-se como ser racional autônomo. Por ser inata, tal liberdade interna (meum vel tuum internum) encontra-se, em Kant, contraposta a todos os direitos adquiridos (meum vel tuum externum). ${ }^{20}$ Embora interno, o direito de ser independente em face de seus semelhantes possui um espaço próprio, ainda que limitado, o qual abarca a posse empírica de objetos (possessio phaenomenon). A sentença jurídica que a legitima é, segundo Kant, analítica por decorrer do princípio de contradição, segundo o qual quem me desloca do chão sobre o qual estou ou me tira a maçã que seguro nas mãos afeta o meu interno (das innere Meine), quer dizer, minha liberdade relativa a coisas suscetíveis de apropriação pelo homem, possibilitada pela razão prática. ${ }^{21} \mathrm{~A}$ possibilidade do direito possessivo resulta de uma suposição jurídica por exclusão. A ação de deter um objeto é justa, quando a máxima que leva à posse empírica não fere a liberdade de qualquer um segundo uma lei universal. Em contrapartida, um objeto fora de mim pode ser concebido de duas maneiras: ou trata-se de algo distinto de mim (do sujeito) ou localiza-se em outro lugar no espaço ou no tempo. Somente no primeiro caso, a posse pode ser tomada por racional, ao passo que no segundo seria necessário denominá-la de empírica. Kant define: "Uma posse inteligivel (caso seja possivel uma tal) é uma posse sem detenção (Inhabung)". ${ }^{22}$

De acordo com o axioma geral do direito, "uma ação é justa quando, por ela ou conforme suas máximas, a liberdade de arbítrio de um pode coexistir com a liberdade de qualquer outro segundo uma lei universal" (Doutrina do Direito, Introdução/parágrafo C). ${ }^{23}$ Para que $\mathrm{o}$ axioma não fique limitado à posse física, é necessário o conhecimento da possibilidade de um objeto (Gegenstand) no qual estão abstraídas as condições empíricas da posse, insuficientes para constituir um conceito de posse jurídica, de forma a poder chamar de meu um objeto, mesmo que não o retenha junto a mim. Sem a possibilidade da posse racional, eu não poderia considerar minha a maçã, a qual não mais guardo comigo. Tampouco seria injusta a ação de alguém que impedisse que eu a recuperasse ou, inversamente, quem furtasse uma maçã que eu detinha nas mãos - por mais que isso desrespeite a minha inata liberdade alusiva à posse - não estaria lesando meu exterior, a não ser que pudesse afirmar que continuo na posse do objeto, ainda

19 Ibidem, parágrafo 17 [16], p. 77.

20 Ibidem, p. 46-47 (Divisão da Doutrina do Direito/B).

21

Ibidem, p. 39. 
que não mais fisicamente. Em ambos os casos, eu não estaria em condições de chamar o objeto de meu, não houvesse a possibilidade do meu exterior (des äusseren Meinen), "cujo obstáculo de fazer uso dele constituiria lesão, conquanto não esteja eu de posse dele (não seja detentor do objeto)". ${ }^{24}$

A possibilidade da posse jurídica não resulta analiticamente do direito inato de poder possuir objetos, uma vez que o meum vel tuum internum não engloba, por definição, o meu externo. Nem a possibilidade nem a impossibilidade de tal posse constitui predicado do sujeito da frase que enuncia a independência de cada homem face ao livre-arbítrio de seu igual. Instada por uma dialética de tese e antítese, a razão é impelida (genötigt) a fazer a crítica jurídico-prática racional, acabando por ser forçada (genötigt) a distinguir, em seu uso jurídico-prático, entre uma posse fenomenal (in der Erscheinung) e uma posse inteligível. Para Kant, as asserções antinômicas "é possível ter algo externo como meu, embora não esteja na posse desse algo" e "não é possivel ter algo externo como meu, quando não estou na posse desse algo" são ambas verdadeiras, contanto que se entenda por posse, na primeira afirmação, a empírica e, na segunda, a puramente inteligivel" ${ }^{25}$ A possibilidade da posse meramente racional, ou seja, a dedução do conceito nãoempírico de posse funda-se sobre o postulado jurídico da razão prática, segundo o qual "é dever jurídico proceder com relação a outros de modo tal que o externo (utilizável) possa também tornar-se o seu de qualquer um". ${ }^{26}$ Em suma, a sentença acerca de tal possibilidade é sintética e "pode servir de tarefa para a razão", de acordo com Kant, mostrando "como é possivel a priori que um tal sentido estendese para além do conceito empírico de posse". ${ }^{27}$

Traço marcante da dedução kantiana do estado jurídico da propriedade não está apenas na tese de que o direito é solidário da razão prática, mas no fato sui generis de o filósofo transcendental manter a primazia da moral para a esfera juridica sem, contudo, inferir princípios de direito do imperativo categórico, de modo simétrico como o fato da razão é, para Kant, um dado genuinamente racional, à revelia da impossibilidade de deduzi-lo da razão teórica. Com isso, Kant não apenas esvazia o balão de ensaio dialético de Hobbes, mas desacredita simultaneamente juristas e filósofos, na medida em que estes fundamentam moralmente ad hoc o direito e aqueles elevam a moral acima do direito positivo sem, porém, terem a mínima idéia sobre o que fazer com a moral na esfera jurídica. Kant não deduz o direito do imperativo categórico. Mas, ao tratar do direito, também não anacroniza a moral. Segundo o filósofo, o imperativo categórico permite que haja vinculações de ordem jurídica mas, por si, não as impõe. O postulado jurídico equivale, para Kant, a uma lei permissiva (lex permissiva) da razão prática. ${ }^{28}$ Esse fato autoriza algo que não poderia ser deduzido de simples conceitos de direito, ou seja, confere ao indivíduo o direito de impor aos demais uma vinculação que de

24 Ibidem, parágrafos 4 e 5, p. 54-56.

25 Ibidem, parágrafo 7, p. 62.

26 Ibidem, parágrafo 6, p. 59.

27 Ibidem, p. 57.

28 BRANDT, Reinhard. Das Erlaubnisgesetz, oder: Vernunft und Geschichte in Kants Rechtslehre. In; Rechtsphilosophie der Aufklärung. Berlin/New York: de Gruyter, 1982, p. 233-285. 
outro modo não teria. Kant arremata: "A razão quer (will) que isto valha como postulado e, na verdade, como algo da razão prática, que por esse seu postulado a priori se amplia (erweitert)" ${ }^{29}$

Por um lado, o postulado jurídico, enquanto Erlaubnisgesetz (lei permissiva) procede de imediato do imperativo categórico como um Faktum. Sob este aspecto, vale a formulação moral de que se é necessário agir de acordo com tal princípio de direito (Rechtsgrundsatz) também tem que ser (muss) possivel uma posse meramente jurídica (rechtlich). Por outro lado, não se trata de uma dedução pura e simples, mas de um procedimento intelectual que estende, por meio de uma lei permissiva geral, o imperativo categórico ao postulado jurídico da razão prática. A dedução opera com uma alternativa segundo a qual tão-somente duas leis da razão, desprovidas de qualquer elemento empírico, podem estabelecer o que vale universalmente para o meu e 0 teu de objetos relacionados com o livre-arbítrio: uma proibição geral ou uma permissão geral, de acordo com a qual, respectivamente, ou cada objeto ou nenhum objeto do arbitrio pode vir a ser um meu/teu exterior ${ }^{30} \mathrm{~A}$ partir do postulado jurídico da razão prática, a primeira alternativa é descartada. "Uma máxima", escreve Kant, "de acordo com a qual, viesse ela a ser lei, um objeto do arbitrio tivesse que tornar-se em si (objetivamente) um objeto sem dono (herrenlos/res nullius), seria injusta" (Doutrina do Direito, parágrafo 6). ${ }^{31}$

A dedução não acaba em uma conclusão negativa porque a razão é prática. Sem qualquer procedimento negativo, porém, o resultado da operação intelectual deveria resultar de um postulado jurídico que fosse imanente ao meu/teu interior (meum vel tuum internum), isto é, ser inferido da liberdade como ratio essendi da lei moral. Tal liberalismo moralizante exigina, por um lado, uma bem-sucedida dedução da ratio cognoscendi da liberdade a partir da razão teórica e, por outro, a equiparação entre lei prática da razão e o postulado jurídico-racional. Kant chama expressamênte atenção para o fato de que esse não é o caso para aquilo que a razão quer com o seu postulado jurídico. O filósofo escreve: "Em um postulado teorético a priori ter-se-ia, na verdade (segundo o que foi dito na Crítica da Razão Pura), que acrescentar ao conceito dado uma intuição a priori, juntar-lhe algo da posse do objeto. Ocorre que nesse princípio prático procede-se de maneira invertida (wird umgekehrt verfahren), e todas as condiçōes da intuição, que fundamentam a posse impírica, têm que ser descartadas (não levadas em conta) para poder dilatar o conceito da posse para além do conceito empírico e poder dizer que todo objeto exterior do arbítrio que tenho (e também só contanto que eu) em meu poder (Gewalt) pode ser considerado juridicamente como meu, ainda que não esteja da posse dele" ${ }^{32}$ Em outras palavras, a propriedade não é, para Kant, um direito natural, provindo de um estado apolítico de individuos que convivem solitariamente . uns com os outros, mas é o pressuposto racional do estado político de direito.

29 KANT. Op. cit., parágrafo 6, p. 58.

30 Formulação ligeiramente alterada no vemáculo de HERB \& LUDWIG. Naturzustand, Eigentum und Staat. Immanuel Kants Relativierung des "Ideal des hobbes". In: Kant-Studien, 83. Jahrgang (1993), p. 290.

31 KANT. Op. cit., p. 57 .

32 Ibidem, p. 58-59. 
Em sua dedução, Kant nega-se não apenas a remeter a propriedade ao modelo do state of nature lockeano que, por sua originariedade, a viesse legitimar socialmente, mas também declina confiá-la ao deus mortal hobbesiano que, como sujeito autorizado, a pudesse impor pela força como direito fundamental. ${ }^{33}$ Mesmo onde Kant estabelece uma congruência indiscernivel entre direito e coerção exterior, a última não é derivada do monopólio da força, inerente ao moderno Estado de direito (Doutrina do Direito, Introdução/parágrafos D, C e E).

Para Kant, a propriedade não afeta as relações entre homens e coisas, senão que altera substancialmente as relações do indivíduo com seus semelhantes. $\mathrm{Ob}$ jeto do que o filósofo chama de dedução não são as diversas constelações empiricas que determinam o contato dos homens com os corpos mas, única e exclusivamente, o arbitrio unificado de sujeitos jurídicos que queiram fazer uso das mesmas coisas como objetos de seus respectivos livre-arbítrios. Formulado em termos negativos, vale dizer: a propriedade é impensável sem uma reciprocidade vinculadora do meu e do teu exterior sob leis públicas, ou seja, ela é inviável à revelia de leis universais que tornam compativeis as relações externas dos homens entre si. Segundo Kant, tais condições jurídicas estão dadas de forma peremptória somente no estado civil (bürgerlicher Zustand). Por conseguinte, quando Kant remete, no direito público, à obrigação deontológica de dever celebrar um contrato originário (Doutrina do Direito, parágrafo 42), ${ }^{34}$ ele tem à disposição o princípio da legislação do estado de direito, bem como uma formulação de vinculação políticofundamental: "Se tem que ser juridicamente possível", escreve ele, "ter como seu um objeto exterior, assim é também necessário estar facultado ao sujeito constrangir cada semelhante, com quem veio a ter uma controvérsia sobre o meu/teu de um objeto qualquer, a aderir junto com ele a uma constituição civil" 35

Ao tematizar posteriormente o status naturae, Kant faz o caminho inverso de Hobbes, seguindo a trilha do exeundum est de volta, rumo a um estado natural provisório sob um ponto de vista jurídico. Com isso, Kant revela ser um contratualista às avessas, quer dizer, todo ato contratual positivo implica a idéia de contrato. ${ }^{36}$ Por não ser um transformista ético, ele acaba tendo com Hobbes um parentesco maior que com Rousseau. Kant privilegia em Hobbes a capacidade de resistir ao fascínio da dialética que, já no teórico inglês, parece guardar a sete chaves o

33 Como aqui: HERB \& LUDWIG. Op. cit. p. 287. Outra opiniāo. HOFMANN, Hasso. Zur Lehre vom Naturzustand in der Rechtsphilosophie der Aufklärung. In: BRANDT. Op. cit., p. 27.

34

KANT. Op. cit., p. 124

Ibidem, parágrafo 8 , p. 63.

O contrato perfaz, também em Kant, uma seqüência de sucessōes devidamente ordenadas. Mas a constituição juridica de contrato obedece, para o filósofo, a uma consumação intelectual simultânea, impossivel de ser pensada em atos temporais sucessivos. Cf. ROHDEN, Valério. Razão e direito. In: Racionalidade e ação. Porto Alegre: Editora da Universidade/UFRGs, 1992, p. 131-132. A dedução do conceito da aquisição originária de propriedade, sumariada por Kant nos parágrafos 14 e 16 (17) da Doutrina do Direito, constitui um contrato real, sem quaisquer antecedentes de negócio bilateral com obrigaçōes sinalagmáticas. A manifestação da vontade aquisitíva é unilateral e pode ocorrer por meio da ocupação (Bemächtigung). Feita a apreensão do objeto, segue a declaração (Bezeichnung) năo-receptícia acerca da posse e do ato volitivo por parte do possuidor, excluindo qualquer outro do uso desse objeto. Por fim, a apropriação (Zueignung) é concebida como ato de uma vontade exterior universalmente legisladora (na idéia), pelo qual todos os demais ficam comprometidos a concordar com o arbítrio do possuidor, ao fazer-se proprietário da coisa. 
segredo da filosofia política moderna. Diferentemente de Rousseau. Ele confiou antecipadamente à eticidade substancial o que não conseguiu resolver com critérios normativos: o conflito entre a triade da modernidade filosófica - o homem, o burguês e $o$ cidadão.

\section{Considerações finais}

O direito é, para Kant, um assunto racional e não um negócio da melhor cultura, do mais alto valor ou da divindade menos cruel. Todo moralismo que responde ao acaso às leis externas, seja porque a moral teria elevado o homem acima do lugar que a natureza lhe reserva, seja porque todo bom cidadão carregaria consigo uma apólice ética e estaria, assim, imune ao positivismo jurídico, acaba em hipocrisia, segundo Kant, tão logo seja pronunciada a palavra propriedade. Kant é uma avis rara porque sua ética não dá, ontem como hoje, oportunidade à melhor das conveniências sociais - a aquisição da propriedade pelo trabalho. Assim como todo milionário honesto foi lavador de pratos, burgueses bem-sucedidos começaram como engraxates. De acordo com o ônus da prova desta teoria de aquisição, toda propriedade fática constitui um documento oficial a favor do dono como superproletário de um lumpenproletário original. Quem tem algo é porque trabalhou ou, em versão mais sofisticada, "Deus ajuda a quem madruga". Sob perspectiva kantiana, não se precisaria ter esperado pelo adeus ao trabalho, em nosso século, para saber que a propriedade não está ancorada na relação do homem com os objetos materiais por ele trabalhados.

Kant encara o problema do Estado como solúvel mesmo para um povo de diabos, desde que providos de entendimento. Preâmbulo crítico desse realismo político é a posição teórico-transcendental que não situa a propriedade no plano dos objetos, mas sim no plano das relações externas dos homens entre si, onde, segundo Kant, os arbítrios são Fakta uns para os outros (Doutrina do Direito, Introdução/B). Em suma, enquanto a independência (Selbständigkeit) é um dos três direitos básicos (Grundrechte), a propriedade não constitui um direito fundamental, mas assinala, em Kant, uma construção da razão.

\section{Referências bỉliográficas}

BARBOSA-FLHO, Balthazar. Condições da autoridade e autorização em Hobbes. In: Filosofia Politica 6. Porto Alegre: L\&PM, 1989, p. 63-75.

BENJAMIN, Cássio C. Hegel e os três modos de passagem do Estado de Natureza ao Estado de Direito. In: Ética e Filosofia Politica, v. 2, n. 1, jan./jun. 1997, p. 93-108.

BRANDT, Reinhard. Das Erlaubnisgesetz, oder: Vermunft und Geschichte in Kants Rechtslehre. In: Rechtsphilosophie der Aufklärung. Berlin/New York: de Gruyter, 1982, p. 233-285.

EBBINGHAUS, Julius. Das kantische System der Rechte des Menschen und des Bürgers in seiner geschichtlichen und aktuellen Bedeutung. In: Gesammelte Aufsätze, Vorträge und Reden. Hildesheim, Olms Verlagsbuchhandlung, 1968, p. 161-193.

GERHARDT, Volker. Eine kritische Theorie der Politik über Kants Entwurf Zum ewigen Frieden. In: ROHDEN, Valério (coord.). Kant e a instituição da paz. Porto Alegre: Ed. Universidade-UFras \& Goethe Institut-ICBA, 1997, p. 19-38; versão portuguesa, p. 39-57.

HABERMAS, Jürgen. Die klassische Lehre von der Politik in ihrem Verhältnis zur Sozialphilosophie. In: Theorie und Praxis. 3. Aufl. Frankfurt a/Main, 1974, p. 48-88. 
Kants Idee des ewigen Friedens - aus dem historischen Abstand von 200 Jahren. In: Die Einbeziehung des Anderen. Studien zur politișchen Theorie. 2. Aufl. Frankfurt a/Main: Suhrkamp, 1997, p. 192-236.

HEGEL, Georg-W. Wissenschaftliche Behandlungsarten des Naturrechts, seine Stelle in der praktischen Philosophie, und sein Verhältnis zu den positiven Rechtswissenschaften. In: Jenaer Kritische Schriften (II). Hrsg. von Hans Brockard und Hartmut Buchner. Hamburg: Meiner, 1983, 90-178.

HERB, Karlfriedrich, LUDWIG, Bernd. Naturzustand, Eigentum und Staat. Immanuel Kants Relativierung des "Ideals des hobbes". In: Kant-Studien, 83. Jahrgang (1993), p. 283-316.

. Kants kritisches Staatsrecht. In: Annual Review of Law and Ethics (1994), p. 431-478.

HOBBES, Thomas. The cive or the citizen. Ed. by Sterling P. Lamprecht. Westport, Conn.: Greenwood Press, 1982.

_Leviathan. Ed. by Richard Tuck. Cambridge/New York: Cambridge University Press, 1991.

HOFMANN, Hasso. Zur Lehre vom Naturzustand in der Rechtsphilosophie der Aufklärung. In: BRANDT Reinhard (Hrsg). Rechtsphilosophie der Aufklärung. Berlin/New York: de Gruyter, 1982, p. $12-46$.

KANT, Immanuel. Vom Verhältnis der Theorie zur Praxis im Staatsrecht. In: Über den Gemeinspruch: Das mag in der Theorie richtig sein, taugt aber nicht für die Praxis / Zum ewigen Frieden. Hrsg. von Heiner F. Klemme, Hamburg: Meiner, 1992, p. 1-48.

- Metaphysische Anfangsgründe der Rechtslehre. Hrsg. von Bernd Ludwig. Hamburg: Meiner, 1986.

KERSTING, Wolfgang. Wohlgeordnete Freiheit. Immanuel Kants Rechts- und Staatsphilosophie. Berlin: New York: de Gruyter, 1984.

LUDWIG, Bernd. Kants Rechtslehre. Hamburg: Meiner, 1988.

—. Kants vernunftrechtliche Staatskonzeption. In: Prima philosophia I (1988), p. 107-130.

MADANES, Leiser. Hobbes e o poder arbitrário. In: Discurso 28, 1997, p. 89-126.

ROHDEN, Valério. Razão prática e direito. In: Racionalidade e ação. Porto Alegre: Editora da Universidade/UFrGs,1992, p. 124-144.

STRAUSS, Leo. The political philosophy of Hobbes. Chicago: University of Chicago press, 1952. 